\title{
A survey of respiratory disease in cotton operatives \\ Part II. Symptoms, dust estimations, and the effect of smoking habit
}

\author{
A. J. FOX, J. B. L. TOMBLESON, A. WATT, and A. G. WILKIE \\ Medical Services Division and The Industrial Hygiene Section of HM Factory Inspectorate, \\ Department of Employment, Chepstow Place, London W.2
}

Fox, A. J., Tombleson, J. B. L., Watt, A., and Wilkie, A. G. (1973). Brit. J. industr. Med., 30, 48-53. A survey of respiratory disease in cotton operatives. Part II. Symptoms, dust estimations, and the effect of smoking habit. In association with a survey of cotton workers dust levels were measured in 11 of the mills. Levels varied from $1.15 \mathrm{mg} / \mathrm{m}^{3}$ to $4.8 \mathrm{mg} / \mathrm{m}^{3}$ excluding fly. Analysis of the survey of workers in relation to the dust levels showed an increase in abnormal symptoms and a greater reduction in ventilatory function in those exposed to the higher dust concentrations. No such relationship was found between dust concentration and the prevalence of bronchitic symptoms. Smokers showed a higher frequency of byssinotic symptoms 'and a greater loss of ventilatory function than non-smokers at all levels of dust exposure. The correlation between dust levels and the frequency of byssinotic symptoms and the loss of ventilatory function was increased by including a time factor. By expressing the dust exposure as $\mathrm{mg}$ years $/ \mathrm{m}^{3}$ it can be predicted that approximately $10 \%$ of subjects exposed to $0.5 \mathrm{mg} / \mathrm{m}^{3}$ of dust for 40 years will have the symptoms of byssinosis.

The first part of the survey of cotton workers described in Part I of this paper shows that byssinosis was still occurring in the Lancashire cotton mills. Therefore, with the assistance of the Industrial Hygiene Section of HM Factory Inspectorate, dust level estimations were made in certain of the factories at the time of the second round of the survey. These measurements excluded coarse particles ('fly') in the hope that they would represent more closely than previous studies (Roach and Schilling, 1960) that part of the dust giving rise to symptoms (Molyneux and Tombleson, 1970). As already described in the first part of the paper, the survey of workers included observations on the symptoms of byssinosis, the symptoms of bronchitis, smoking habits, and measurements of ventilatory function. The rela- tionships between these and the dust concentrations are the subject of this part of the paper.

\section{Methods}

The population, methods of estimating symptoms of byssinosis and bronchitis, and the methods of measuring ventilation have been described in Part $I$ of this paper.

\section{Classification of smoking habit}

In the course of examination each subject was asked about his smoking habit and subsequently classified according to the following classification:

Non-smoker - Subject who has never smoked as much as one cigarette per day or $1 \mathrm{oz}$. of tobacco a month, for as long as one year 
Ex-smoker - Subject who has smoked (see 'nonsmoker') and who ceased smoking more than one month before examination

Smoker

Grade $1-1-14$ cigarettes per day and/or up to $3 \mathrm{oz}$. tobacco per week

Grade 2 - 15-24 cigarettes per day and/or up to $6 \mathrm{oz}$. tobacco per week

Grade $3-25+$ cigarettes per day and/or $6 \mathrm{oz}$. or more tobacco per week

The definition of 'ex-smoker' was inadequate for the purposes of detailed analysis because it took no account of:

(a) the number of years since the subject last smoked;

(b) the subject's grade when he smoked;

(c) the reasons for the subject giving up smoking.

The last of these may possibly be the most important because a large number of people give up smoking when they notice an adverse effect on their health.

\section{Dust estimation}

Dust sampling was carried out at a time near but not the same as the second round of the clinical survey. Each gravimetric sample of dust was collected on a glass fibre filter over a period of two to three and a half hours using the Rotheroe and Mitchell pump. The air reaching the glass fibre filter, which was supported in the instrument in a vertical position $5 \mathrm{ft}$ from the floor near working position, was drawn through a pre-filter zone formed by a 12 in. cube of $2 \mathrm{~mm}$ mesh wire gauge. Fly which collected on the gauze was removed manually at appropriate intervals to prevent it accumulating and thus allowing the collection of a mixed sample of fine and medium size dust. The pumps worked at rates of 50-60 litres per minute. Sampling was carried out over a period of a week in four main areas, in opening and blowrooms, two areas in cardrooms, in spinning rooms, and on winding and beaming in winding rooms. Samples were also taken for estimation of the proportion of mineral dust in each area, using a hurricane gravimetric sampler. These results have not yet been correlated with other findings but are the subject of further study. It will be seen, therefore, that dust levels referred to are those of cotton excluding fly (fine plus medium fractions of dust-Roach and Schilling, 1960).

Dust level estimations were made in a group of 11 mills ( 6 coarse, 3 medium, 2 fine) selected on the basis of the prevalence of byssinosis found when 1188 subjects ( 389 males, 799 females) were examined. Individuals were associated with the estimated dust concentration at the site they frequented most. It was not possible to associate 48 individuals who worked in the blowroom (blenders, scutchers, in the cotton chambers or just in the blowing room) because these were all given the same job classification. As the dust levels measured at these various sites varied considerably these subjects were excluded from the following analysis. The remaining 1140 (343 males, 797 females) have been associated with a dust concentration estimate.

\section{Statistical methods}

The symptoms of byssinosis and bronchitis were both recorded as arbitrary grades. For the purpose of con- structing regression lines these grades were converted into scores of 0 or 1 for each individual. For byssinosis grade 0 was scored as 0 and grades $\frac{1}{2}, 1,2$ were scored as 1. In constructing the figures showing regression lines the percentage of byssinotics was derived from the proportion of workers in each group with a score of 1. For bronchitis those workers without the sputum chest illness syndrome (Lloyd Davies, 1971) were given a score of 0 and those with the syndrome a score of 1 .

In calculating the time-weighted dust concentrations it was assumed that a worker exposed to a certain dust concentration at the time of the survey had been exposed to that same concentration throughout his working life at that job. Therefore, the time-weighted dust concentration $(T W D)=$ dust concentration $\left(\mathrm{mg} / \mathrm{m}^{3}\right) \times$ years of exposure. In the construction of the regression lines it was assumed that the relationships were straight lines for the purpose of this study although the results suggest that they are curves.

\section{Results}

The dust concentrations in the 11 mills are summarized in Table 1. Although there is considerable variation in concentrations between the various mills and between the various workrooms within the mills, the pattern of dust concentration excluding fly is consistent with that shown by previous studies. They varied from $0 \cdot 15$ to $4 \cdot 8 \mathrm{mg} / \mathrm{m}^{3}$.

\section{Dust concentration and byssinosis}

This relationship is shown in Table 2 and Fig. 1 where the workers were grouped into four categories according to the dust concentrations at the time of the study. The prevalence of byssinotic symptoms of grade $\frac{1}{2}$ or more rose progressively from $6.75 \%$ for dust concentrations of under $1.0 \mathrm{mg}$ to $39.24 \%$ for concentrations over $3.0 \mathrm{mg} / \mathrm{m}^{3}$. The regression (Fig. 1) calculated as a straight line gives a value of $1.66 \%$ byssinotics at 0 dust concentration and $32.2 \%$ at a dust concentration of $4.0 \mathrm{mg} / \mathrm{m}^{3}$. The correlation coefficient is $+0 \cdot 25$. However, when this relationship was re-examined, taking into account the years of exposure (time-weighted dust concentrations), the correlation increases (Table 3, Fig. 2). The workers were divided into four dust exposure groups and the straight regression line starts at $-0.6 \%$ at 0 dust exposure and rises to $25 \%$ at $50 \mathrm{mg}$ years $/ \mathrm{m}^{3}$. This is equivalent to 50 years' exposure to $1 \mathrm{mg} / \mathrm{m}^{3}$ or 25 years' exposure to $2 \mathrm{mg} / \mathrm{m}^{3}$. The correlation coefficient is +0.64 .

\section{Dust concentration and bronchitis}

The prevalence of bronchitis in 1140 male and female subjects has been regressed against the dust concentration giving the following line:

$$
\begin{aligned}
& \% \text { bronchitic }= \\
& 6.18+0.55 \times(\text { dust concentration) }
\end{aligned}
$$

with a correlation of $+0 \cdot 07$. This nearly horizontal line, with a low correlation, suggests that the 
TABLE 1

Dust Measurements (Total Dust less Fly) in the 11 Mills (mg/m³)

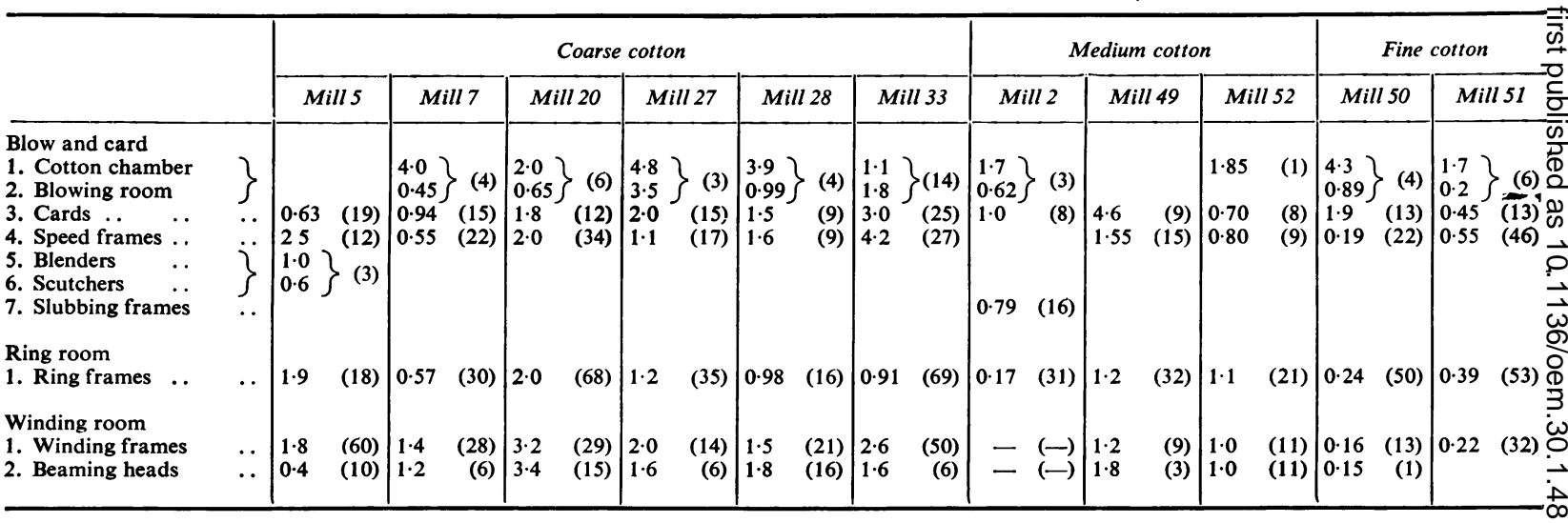

Figures in parentheses represent the number of people examined at that particular site.

TABLE 2

Prevalence of Byssinosis in Dust Exposure Groups

\begin{tabular}{cc|c|c|c}
\hline $\begin{array}{c}\text { Dust group } \\
\left(\mathrm{mg} / \mathrm{m}^{3}\right)\end{array}$ & $\begin{array}{c}\text { No. of } \\
\text { subjects } \\
\text { examined }\end{array}$ & $\begin{array}{c}\text { Mean dust } \\
\text { concentration } \\
\left(\mathrm{mg} / \mathrm{m}^{3}\right)\end{array}$ & $\begin{array}{c}\% \text { Prevalence } \\
\text { of byssinosis } \\
\left(\text { grade } \frac{1}{2} \text { and }\right. \\
\text { over })\end{array}$ \\
\hline $0.0-1.0$ & $\ldots$ & 504 & 0.55 & 6.75 \\
$1 \cdot 1-2.0$ & $\ldots$ & 470 & 1.64 & 12.55 \\
$2 \cdot 1-3.0$ & $\ldots$ & 87 & 2.70 & 17.24 \\
$>3.0$ & $\ldots$ & 79 & 3.74 & 39.24 \\
\hline
\end{tabular}

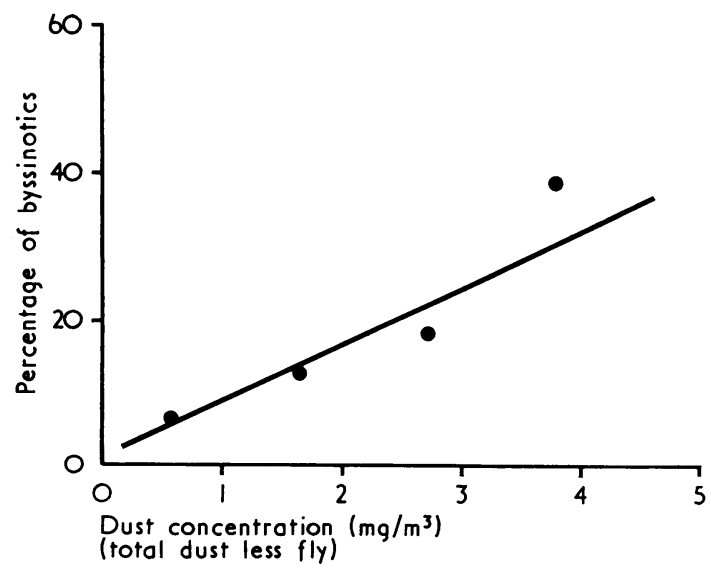

FIG. 1. Percentage of byssinotics regressed against dust concentration. Points represent the means of the groups given in Table 2 (1 140 males and females).

$\%=1.66+7.63 \times$ (dust concentration)

Correlation +0.25
TABLE 3

Prevalence of Byssinosis in Time-Weighted DUST EXPOSURE GROUPS

\begin{tabular}{cc|c|c|c}
\hline $\begin{array}{c}\text { Time-weighted } \\
\text { dust group } \\
\left(m g \text { years } / m^{3}\right)\end{array}$ & $\begin{array}{c}\text { No. of } \\
\text { subjects } \\
\text { examined }\end{array}$ & $\begin{array}{c}\text { Mean time- } \\
\text { weighted dust } \\
\text { measure- } \\
\text { ments } \\
\left(m g \text { years } / m^{3}\right)\end{array}$ & $\begin{array}{c}\% \text { Prevalence } \\
\text { of byssinosis } \\
\text { (grade } \frac{1}{2} \text { and } \\
\text { over })\end{array}$ \\
\hline $0.0-10.0$ & $\ldots$ & 330 & $5 \cdot 75$ & 3.63 \\
$10 \cdot 1-20.0$ & $\ldots$ & 257 & $15 \cdot 34$ & 9.73 \\
$20 \cdot 1-30.0$ & $\ldots$ & 206 & 24.06 & 12.31 \\
$>30.0$ &. & 347 & 48.50 & 22.19 \\
\hline
\end{tabular}

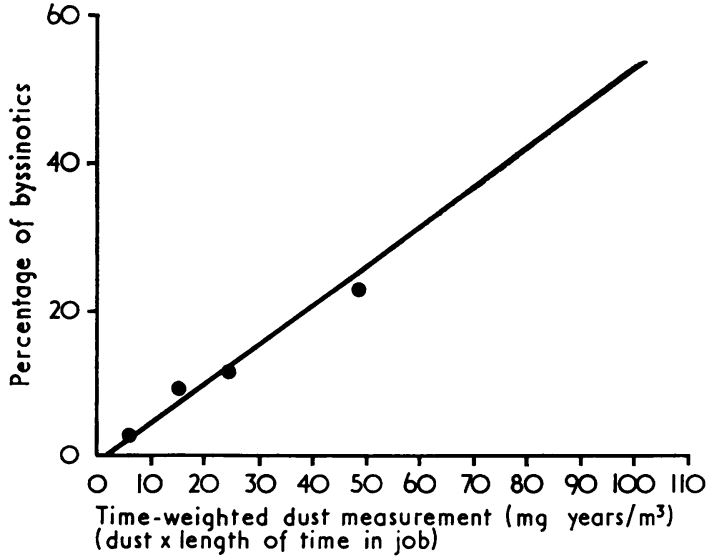

FIG. 2. Percentage of byssinotics regressed against timeweighted dust measurement. Points represent the means of the groups given in Table 3 (1 140 males and females). $\%=-0.62+0.53 \times$ (dust concentration $\times$ years in job)

Correlation +0.64 
prevalence is not dependent on the dust concentration. As previously with byssinosis, the next step was to find the relationship with time-weighted dust measurement. The regression line (Fig. 3 solid line) found was:

$\%$ bronchitic $=$

$5.42+0.06 \times$ (time-weighted dust measurement)

with a correlation of $+0 \cdot 15$, showing slight dependence which might be due to the increase with respect to age.

The prevalence of bronchitis in the 191 controls, used by Lloyd Davies (1971), can be regressed against their ages to give the following line:

$$
\% \text { bronchitic }=-1.2+0.30 \times(\text { age })
$$

with a correlation of $+0 \cdot 5$.

Using this control regression the probability of each cotton worker having bronchitic symptoms at his age was then calculated as though he was an engineering worker. From these estimated probabilities the control (broken) regression line in Fig. 3 was constructed. It is not significantly different from the observed, and this confirms the lack of contribution of cotton dust exposure to the prevalence of bronchitis.

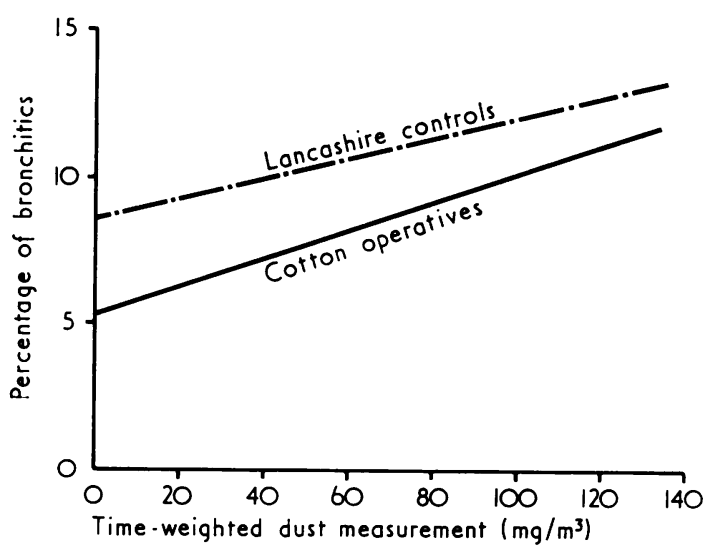

FIG. 3. A comparison of the prevalence of bronchitis in cotton operatives with that in Lancashire males.

\section{Dust exposure, smoking, and ventilatory function}

The results described in Part I of this paper indicated that the $\mathrm{FEV}_{\mathrm{1.0}}$ expressed as a percentage of the value predicted for height and age was a more sensitive indication of disability due to byssinosis than the FVC. Of the 1140 workers for whom relevant dust concentrations were available, 16 failed to record reliable values for $\mathrm{FEV}_{\mathbf{1 . 0}}$, leaving 1124 readings for analysis. Because of the effect of smoking on the $\mathrm{FEV}_{1.0}$ the workers were divided into three groups for the purposes of this analysisnon-smokers, smokers, and ex-smokers. The relatively small number of ex-smokers (48) and the lack of information about how recently they had given up and why makes this group unsuitable for reliable analysis.

The regression lines for time-weighted dust exposure against percentage expected $\mathrm{FEV}_{1 \cdot 0}$ are shown in Figure 4. The equations for the nonsmokers and for the smokers are given as a footnote and the correlations for these lines are not good $(-0.08$ and -0.13 respectively). None of the lines starts at $100 \%$ for zero exposure to dust, indicating that the straight line regressions are probably not the best way of representing the relationship. Table 4 gives the analysis of variance for these regression lines. This indicates that the slope of both lines is significantly different from zero. But although the smokers had significantly lower $\mathrm{FEV}_{\mathbf{1 . 0}}$ values than the non-smokers at all dust levels, the slope of the two lines was not significantly different.

Dust exposure, smoking, and symptoms of byssinosis Using the same method, regression lines were constructed to see whether the three groups, nonsmokers, smokers and ex-smokers, behaved in the same way when analysed for the effect of timeweighted dust concentrations on the frequency of the

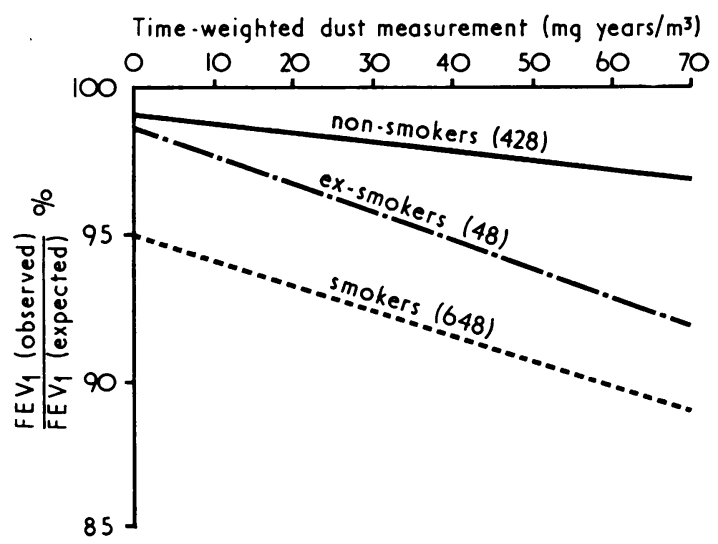

FIG. 4. Effect of smoking on pulmonary ventilation $\left(F E V_{1.0}\right)$ at different levels of time-weighted dust exposure.

'Non-smokers':

$\frac{\text { FEV }_{1.0}(\text { Observed })}{\text { FEV }_{1.0}(\text { Expected })} \%=99.00-0.035 \times($ TWDM $):$

'Smokers': $r=-0.08$

$\frac{\text { FEV }_{1 \cdot 0}(\text { Observed })}{\text { FEV }_{1 \cdot 0}(\text { Expected })} \%=94.68-0.083 \times($ TWDM $):$ $\mathrm{r}=-0 \cdot 13$ 
TABLE 4

ANAlysis of VARIANCE APPlied to Regressions of VeNTILATORY CAPACITY $\left(\right.$ FEV $\left._{1 \cdot 0}\right)$ ON TIME-WEIGHTED DUST MEASUREMENT FOR SMOKERS AND NON-SMOKERS (see Fig. 4)

\begin{tabular}{|c|c|c|c|}
\hline Source of variation & $\begin{array}{l}\text { Sum of } \\
\text { squares }\end{array}$ & D.F. & Significance \\
\hline $\begin{array}{l}\text { Slope of overall line } \\
\text { through both groups }\end{array}$ & $3761 \cdot 50$ & 1 & $P<0.001$ \\
\hline 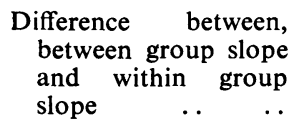 & 8585.93 & 1 & $\mathbf{P}<0.001$ \\
\hline $\begin{array}{l}\text { Difference between } \\
\text { slopes within groups }\end{array}$ & $542 \cdot 44$ & 1 & $\begin{array}{l}\text { Not } \\
\text { significant } \\
(P=0.05)\end{array}$ \\
\hline $\begin{array}{lll}\text { Residual } & \ldots & \ldots\end{array}$ & $373443 \cdot 07$ & 1072 & \\
\hline Total & $386332 \cdot 93$ & 1075 & \\
\hline
\end{tabular}

symptoms of byssinosis. The three regression lines are shown in Fig. 5, with the equations for smokers and non-smokers as a footnote. Again the small number of ex-smokers for whom the information was available are omitted from the subsequent analysis. Neither regression plotted as a straight line passes through zero and the correlation, although closer than that for dust concentration against reduction in $\mathrm{FEV}_{\mathbf{1} \cdot 0}$, is not very good. Although this suggests that the true regression may not be linear the analysis of variance (Table 5) shows that the slopes of both lines differ significantly from zero and that the slope for smokers is significantly steeper than for non-smokers. Non-smokers show an increasing incidence of byssinosis with increasing exposure to dust measured by the time-weighted dust concentration. In smokers the overall frequency of byssinosis is higher and the rate of increase with increasing exposure is greater than in non-smokers.

\section{Discussion}

In this study an attempt has been made to relate the frequency of byssinotic symptoms and other symptoms and signs of chronic respiratory disease to the level and duration of exposure to cotton dust. In the mills where measurements were made it was possible to make a reliable estimate of the current level of exposure of all but 48 of the 1188 workers studied. These 48 worked in blowrooms and cotton chambers where too wide a range of dust values was obtained to be used as a basis for analysis. Elsewhere it seems that the dust concentrations were reliable because a positive correlation is shown between the dust con-

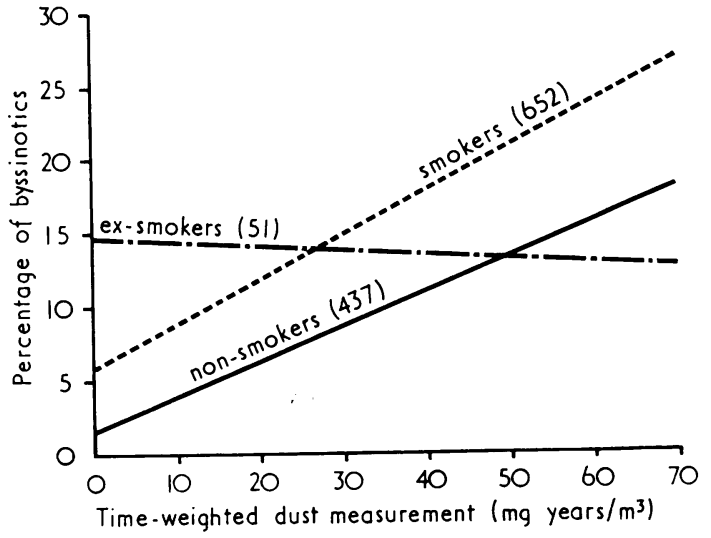

FIG. 5. Effect of smoking on prevalence of byssinosis at different time-weighted dust exposure levels.

'Non-smokers':

$$
\%=1.57+0.23 \times(\text { TWDM }): r=0.27
$$

'Smokers':

$$
\%=5.76+0.30 \times(\text { TWDM }): r=0.25
$$

centration and the frequency of symptoms of byssinosis. This correlation was considerably increased by making allowance for the duration of exposure using time-weighted dust concentrations. The method assumes that the contribution of a year of exposure at a given dust concentration 20 years previously is the same as the contribution of a year's exposure to the same concentration at the time of the study. It also assumes that one year's exposure at a concentration of $2 \mathrm{mg} / \mathrm{m}^{3}$ has the same effect as 2 years at $1 \mathrm{mg} / \mathrm{m}^{3}$. Such assumptions have been used in

\section{TABLE 5}

ANAlysis of Variance aPPlied to Regression of Prevalence of Byssinosis on Time-weighted Dust MEASUREMENTS FOR SMOKERS AND NON-SMOKERS

\begin{tabular}{|c|c|c|c|}
\hline Source of variation & $\begin{array}{l}\text { Sum of } \\
\text { squares }\end{array}$ & D.F. & Significance \\
\hline $\begin{array}{l}\text { Slope of overall line } \\
\text { through both groups }\end{array}$ & $7 \cdot 2765$ & 1 & $P<0.001$ \\
\hline \begin{tabular}{rrr}
$\begin{array}{r}\text { Difference } \\
\text { between group slope }\end{array}$ & \multicolumn{2}{r}{ between, } \\
and within & group \\
slope &.. &.
\end{tabular} & 0.9659 & 1 & $P<0.001$ \\
\hline $\begin{array}{l}\text { Difference between } \\
\text { slopes within groups }\end{array}$ & $11 \cdot 0253$ & 1 & $P<0.001$ \\
\hline Residual & $96 \cdot 7334$ & 1085 & \\
\hline Total & 116.0011 & 1088 & \\
\hline
\end{tabular}
(see Fig. 5) 
estimating the maximum safe levels of exposure for asbestos workers (British Occupational Hygiene Society, 1968). Provided they are correct and that the regression is linear, it is possible to calculate the maximal safe levels for exposure to cotton dust. The acceptable dust level agreed by the Joint Standing Committee to the cotton industry is $0.5 \mathrm{mg} / \mathrm{m}^{3}$ of cotton dust less fly. Assuming a working life exposure of 40 years, approximately $10 \%$ of subjects would suffer from symptoms of byssinosis. The majority of these cases would have only early symptoms.

It has already been shown in Part I of this paper that the symptoms of bronchitis correlate significantly with those of byssinosis and that smoking affects the frequency of symptoms of byssinosis and bronchitis as well as causing a fall in $\mathrm{FEV}_{1 \cdot 0}$. By using the time-weighted dust concentrations it has been possible to show that the extent of dust exposure does not show a positive correlation with the frequency of bronchitic symptoms when due allowance is made for age.

By dividing the workers into smokers and nonsmokers and eliminating the ex-smokers, it has been possible to show that smoking increases the loss of ventilatory function $\left(\mathrm{FEV}_{1 \cdot 0}\right)$ at all levels of dust exposure. This occurs without increasing the loss produced by different levels of dust exposure. Smokers show a greater incidence of byssinosis at all levels of dust exposure. Smokers also show a greater tendency to develop byssinosis with increasing dust exposure than non-smokers. The linear regression lines both suggest an appreciable incidence of byssinosis at 0 dust exposure (non-smokers $1.6 \%$ and smokers $5 \%$ ). This may be due to an overlap of symptoms with bronchitis but it also suggests that the regression should be a curve. Using a straight line relationship in non-smokers, it is possible to recalculate the acceptable level for a 40-year working exposure. A level of $0.37 \mathrm{mg} / \mathrm{m}^{3}$ or a cumulative total of $14.9 \mathrm{mg}$ yrs $/ \mathrm{m}^{3}$ would be expected to result in a $5 \%$ incidence of byssinosis. The same dust level would produce just over $10 \%$ byssinosis in smokers. Ex-smokers were excluded from these calculations because of the small numbers and because of the anomalous findings. In Part I of the paper exsmokers were noted to have a higher frequency of severe byssinosis than even the heaviest smokers, suggesting that workers with severe chest symptoms tend to give up smoking. This is consistent with the findings of the Royal College of Physicians Committee on smoking (1971):

'the commonest reasons given are risks to health, many minor and immediate effects such as cough, repeated colds, and breathlessness being more prominent than the ore remote risks of lung cancer and other serious illness. Most smokers need to experience symptoms from smoking or to be convinced of its ultimate dangers to be persuaded to abandon the habit on grounds of health ...'

Tentative regression lines have been inserted for exsmokers in Figures 4 and 5. Ex-smokers appear to show a greater deterioration of ventilatory function with increasing dust exposure but they are not as severely disabled as smokers at low levels of exposure. The negative slope of the regression in Fig. 5 possibly indicates that at lower levels chest troubles are attributed to smoking and therefore the worker with chest disease gives up smoking; at higher dust levels he might attribute the disease to dust and therefore continue smoking.

Further study is needed to establish whether the assumptions made in using the time-weighted concentration as an estimate of cumulative dust exposure are valid. It may then be possible to fit more valid regressions to represent the effect of cumulative exposure on the incidence of byssinosis.

Mill management and operatives have been most helpful and without their co-operation the survey could not have been made. Our thanks are given to the British Textile Employers' Association, the National Union of Textile and Allied Workers, the Amalgamated Weavers' Association, and the Amalgamated Association of Operative Cotton Spinners and Twiners for their support.

The planning of the survey was carried out by Dr. T. A. Lloyd Davies, now Chief Medical Adviser to the Department of Employment, with the help of Professor R. S. F. Schilling and the late Dr. C. B. McKerrow. The dust estimations were made by the Industrial Hygiene Section of the Chemical Branch of HM Factory Inspectorate. Miss M. E. Laister, Miss P. Ballinger, and Mrs. S. Smith assisted in the organization of the examinations in the mills. The extended consideration of smoking was due to questions raised by $\mathrm{Mr}$. J. H. Locke.

\section{References}

British Occupational Hygiene Society (1968). Hygiene Standards of Chrysotile Asbestos Dust. Pergamon Press, Oxford.

Lloyd Davies, T. A. (1971). Report of Respiratory Diseases in Foundrymen. H.M.S.O., London.

Molyneux, M. K. B., and Tombleson, J. B. L. (1970). An epidemiological study of respiratory symptoms in Lancashire mills 1963-66. British Journal of Industrial Medicine, 27, 225-234.

Roach, S. A., and Schilling, R. S. F. (1960). A clinical and environmental study of byssinosis in the Lancashire cotton industry. British Journal of Industrial Medicine, 17, 1 -9.

Royal College of Physicians (1971). Smoking and Health Now. Pitman Medical and Scientific Publishing Co. Ltd., London.

Received for publication August 4, 1971. 